\title{
Effect of Temperature on the Dynamic Recrystallization of AZ31 Alloy with Pulse Current
}

\author{
Shu-Xia Lin ${ }^{1} \cdot$ Xing-Rong Chu ${ }^{1} \cdot$ Zhen-Ming Yue $^{1} \cdot$ Jun Gao $^{1}$ \\ Received: 3 January 2018/Revised: 6 February 2018/Published online: 26 April 2018 \\ (C) The Chinese Society for Metals and Springer-Verlag GmbH Germany, part of Springer Nature 2018
}

\begin{abstract}
The tensile tests of AZ31 magnesium alloy were carried out under room temperature, 100, 150 and $200{ }^{\circ} \mathrm{C}$ with and without pulse current. The effect of temperature on dynamic recrystallization (DRX) of AZ31 alloy was studied at different conditions. One-parameter approach was used to analyze the critical conditions of DRX, the critical stress was obtained under different temperatures, and the related results were validated by metallography observation. The results showed that DRX of AZ31 alloy occurred at $200{ }^{\circ} \mathrm{C}$ without pulse current. When pulse current with $150 \mathrm{~Hz} / 50 \mathrm{~V}$ parameter was applied at room temperature, DRX occurred, while DRX was not completed until temperature over $150{ }^{\circ} \mathrm{C}$. With the analysis result of critical conditions of DRX based on one-parameter approach, the relationship between critical stress and peak stress obtained in this present study is $\sigma_{\mathrm{c}}=(0.746-0.773) \sigma_{\mathrm{p}}$.
\end{abstract}

Keywords AZ31 alloy · Electroplasticity · Dynamic recrystallization · One-parameter approach

\section{Introduction}

Magnesium (Mg) alloys have poor formability caused by their hexagonal close-packed (HCP) structure. The limited slip system restricts their formability and application fields. However, Mg alloys are prone to dynamic recrystallization (DRX), and it is the main mechanism to refine grains and improve their mechanical performance $[1,2]$. DRX behavior is related to the strain rate, deformation temperature and deformation degree [3]. It was generally supposed that DRX has occurred before the peak stress appears in flow stress curve while the curve does not show significant characteristic of DRX [4]. Poliak et al. [5] suggested that the DRX critical condition corresponds to the minimum values of the $-(\partial \theta / \partial \sigma)-\sigma$ and $-(\partial \ln \theta /$ $\partial \ln \varepsilon)-\varepsilon$ plots, where $\theta(\theta=\mathrm{d} \sigma / \mathrm{d} \varepsilon)$ is the strain hardening rate. Based on the one-parameter approach, the DRX critical condition can be obtained, which has been

Available online at http://link.springer.com/journal/40195

Zhen-Ming Yue

yuezhenming@sdu.edu.cn

1 School of Mechanical, Electrical and Information Engineering, Shandong University, Weihai 264209, China successfully applied to stainless steel, copper and $\mathrm{Mg}$ alloy deformation $[3,6,7]$.

Pulse current-assisted forming is widely used in material forming, which has significant effects on mechanical properties of materials [8,9]. Yao et al. [10] confirmed that the drawing stress and the work hardening rate of wires were significantly reduced due to the increasing movement of dislocations caused by current pulses, and the work hardening coefficient decreased with increasing frequency. Conrad et al. [11] pointed out that the current pulses enhances recrystallization and reduces the temperature for the onset of recrystallization and proposed that the electric current caused the higher mobility of dislocations. Xu et al. [12] reported the enhanced recrystallization rate of $\alpha$-Ti plate due to applied electric current. Park et al. [13] indicated that electric current accelerates a higher nucleation rate in recrystallization and reduces the activation energy for recrystallization. Thus, it can be seen that pulse current is beneficial to DRX of $\mathrm{Mg}$ alloy at low temperature $[14,15]$. Xu et al. [16] reported that the DRX temperature of AZ31 alloy is about $376 \mathrm{~K}$ with $200 \mathrm{~Hz} / 80 \mathrm{~A}$ current parameter, while the computation procedure is complex. Chu et al. [17] studied the critical condition of AZ31 alloy at different voltages by one-parameter approach, and the results are verified by means of metallography observation. It is indicated that one-parameter approach can be used to 
analyze the critical condition of electroplastic forming of AZ31 alloy. The accuracy DRX critical conditions can effectively control the material microstructure and property during forming process. Besides, the DRX critical condition is beneficial to the study of deformation behavior and electroplastic forming mechanism of $\mathrm{Mg}$ alloy.

In this work, uniaxial tensile tests of AZ31 alloy were carried out with and without pulse current, respectively. The effect of temperature on DRX under different forming conditions was studied. The critical condition for DRX was obtained by the one-parameter approach, and the related results were validated by means of metallography observation. The relationship between critical stress and peak stress was obtained in tensile tests with pulse current.

\section{Experimental}

AZ31 Mg alloy sheets with a thickness of $0.8 \mathrm{~mm}$ were used in tensile tests. The specimens were cut along the rolling direction, and their dimensions are shown in
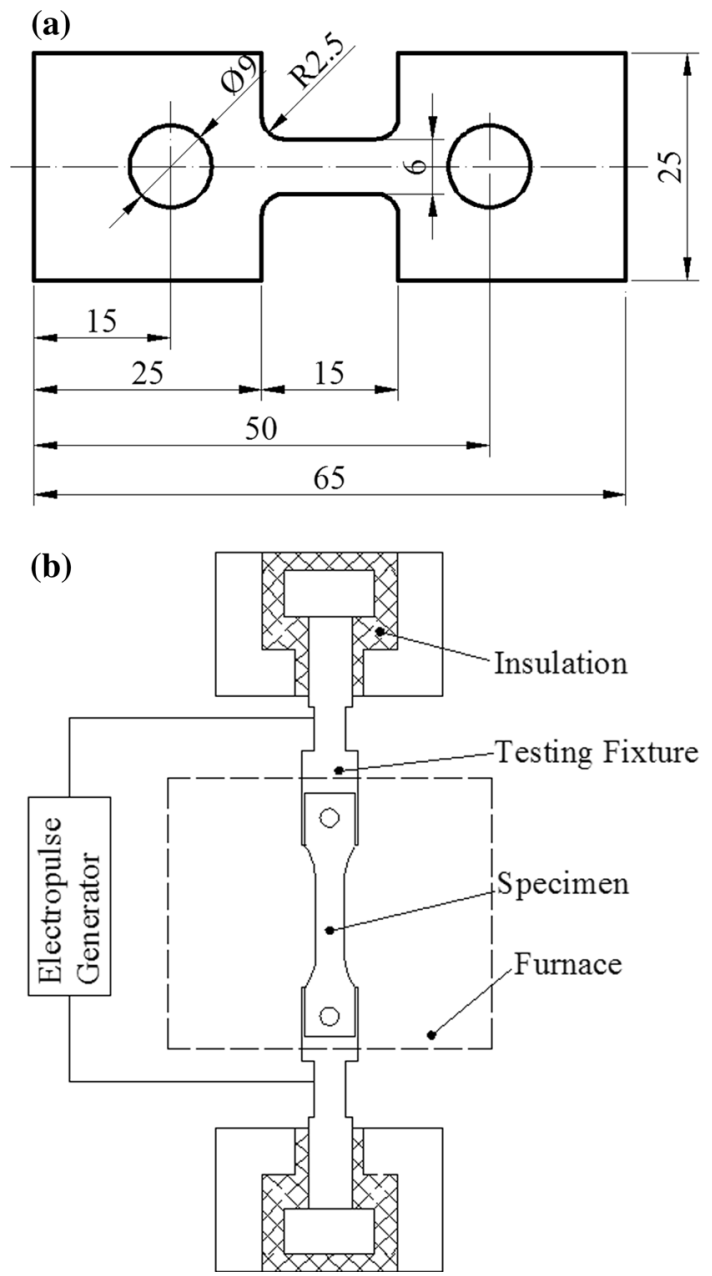

Fig. 1 Sketch of a specimen; b electric tensile test setup
Fig. 1a. The tensile tests were carried out on a universal testing machine with a speed of $5 \mathrm{~mm} / \mathrm{min}$. A pulse generator was used to discharge the applied positive direction multiple pulses. The test temperature was monitored by three thermocouples in heating furnace. The specimens were uniaxial stretched at room temperature, 100, 150 and $200{ }^{\circ} \mathrm{C}$ with and without pulse current, respectively. The tensile test started when the setting temperature was reached and meanwhile the current parameter of $150 \mathrm{~Hz} / 50 \mathrm{~V}$ was applied to the tests with pulse current. The samples for microstructure analysis were polished and etched in etchant (1 $\mathrm{g}$ picric acid, $10 \mathrm{ml}$ ethanol, $1 \mathrm{ml}$ acetic acid and $2 \mathrm{ml}$ distilled water) for $15 \mathrm{~s}$, and the microstructure was analyzed by a ZEISS optical microscope.

\section{Results}

\subsection{Strain-Stress Curves}

The true stress-strain curves of AZ31 alloy under different forming conditions are shown in Fig. 2. With increasing temperature, the flow stress reduces and tensile elongation decreases gradually (Fig. 2a). As can be seen in Fig. 2b, the flow stress decreases more sharply and the process of work hardening is shortened compared with the without current test at the same temperature in Fig. 2a. However, as shown in Fig. 2b, the elongation at rupture with pulse current is almost constant at different temperatures. To avoid arc discharge, the pulse current is turned off before the specimen fractures and the flow stress increase rapidly without current. It is obvious that the pulse current has strong effect on the flow stress decreasing.

\subsection{Critical Stress for Initiation of DRX}

Based on the principles of irreversible thermodynamics, the corresponding critical stress of DRX of AZ31 alloy is the minimum value of the $-(\partial \theta / \partial \sigma)-\sigma$ curve. The curves in Fig. 2 are analyzed by this one-parameter approach, and the results are shown in Fig. 3. Figure 3a, b shows that the relationship between the strain hardening rate $(\theta)$ and the stress $(\sigma)$ under different conditions. Figure $3 \mathrm{c}$, d shows the $-(\partial \theta / \partial \sigma)-\sigma$ curve, derived from Fig. 3a, b, respectively. The minimum values of curves Fig. $3 c$, $d$ correspond to the DRX critical stresses. As a result, the critical stress of DRX of AZ31 alloy at different temperatures with and without pulse current can be obtained. The inflection points of the $\theta-\sigma$ curves can be observed in Fig. 3a, b, while the minimum value cannot be found in Fig. $3 c$ until temperature reaches $200{ }^{\circ} \mathrm{C}$, which indicates DRX does not occur when temperature is below $200{ }^{\circ} \mathrm{C}$ without current [18]. While with pulse current applied, all $-(\partial \theta / \partial \sigma)-\sigma$ curves show 

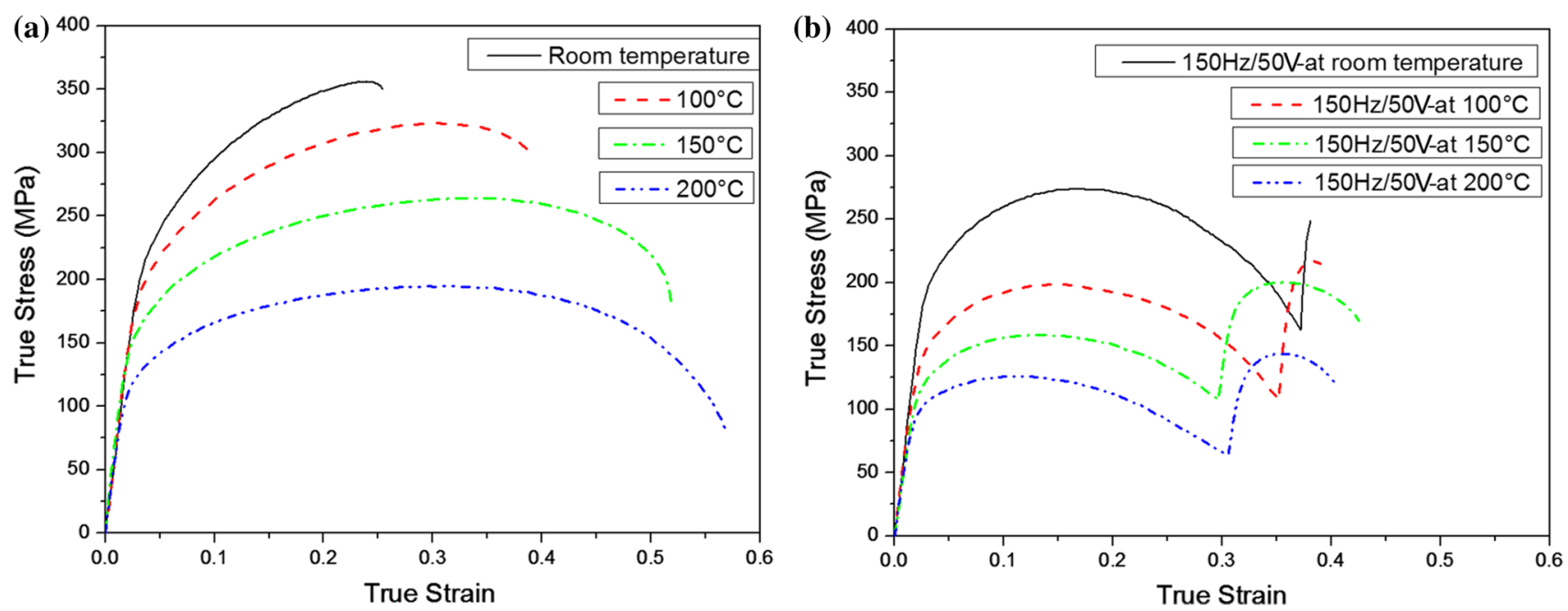

Fig. 2 True stress-strain curves under various temperatures: a without current; $\mathbf{b}$ with current
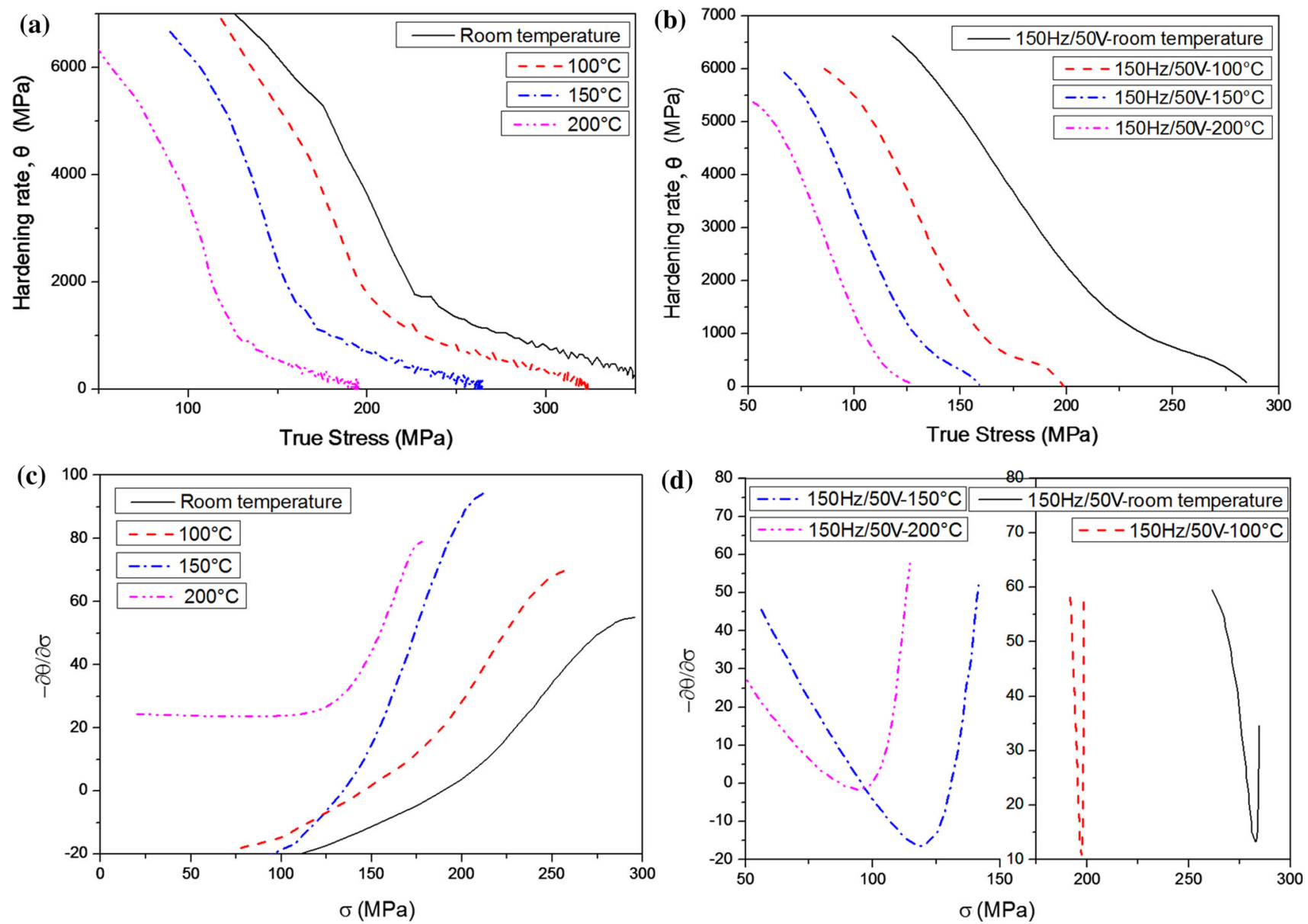

Fig. 3 Curves of $\theta$ and $\sigma$ under different conditions: a, b $\theta-\sigma$; $\mathbf{c}, \mathbf{d}(\partial \theta / \partial \sigma)-\sigma$

the minimum value. Based on the results above, it can be concluded that the inflection point on the $\theta-\sigma$ curves is not corresponding to the minimum value on the $-(\partial \theta / \partial \sigma)-\sigma$ curve, and the pulse current can accelerate the occurrence of DRX of AZ31 alloy. 


\subsection{Microstructure Evolution}

The occurrence of DRX of AZ31 alloy can also be analyzed by metallographic observation. Figure 4 shows the microstructures in the fracture zone of the specimens under different conditions. As shown in Fig. 4a, coarse grains are elongated along the deformation direction and a little twinning (marked in the red circles) exists at $150{ }^{\circ} \mathrm{C}$. After temperature reaches $200^{\circ} \mathrm{C}$, fine grains appear at serrated grain boundaries, which is a typical feature of DRX (Fig. 4b). When the current is applied at room temperature (Fig. 4c), coarse grains are elongated and a large number of equiaxed grains are observed, while the twinning is disappeared. When the temperature is increased to $100{ }^{\circ} \mathrm{C}$, large grain boundary becomes serrated and fine DRX grains are observed in the grain boundary and triangle of grain boundary (Fig. $4 \mathrm{~d}$ ). When the temperature is increased to $150{ }^{\circ} \mathrm{C}$, more equiaxed grains are observed. As can be seen in Fig. 4f, DRX is basically completed and the microstructure consisted mainly of inhomogeneous recrystallized grains at $200{ }^{\circ} \mathrm{C}$.

The above microstructure evolution analysis indicated that DRX does not take place until at $200{ }^{\circ} \mathrm{C}$ without current. When pulse current with $150 \mathrm{~Hz} / 50 \mathrm{~V}$ parameter is applied, DRX occurs at room temperature. However, the DRX is incomplete at room temperature and at $100{ }^{\circ} \mathrm{C}$. After the temperature increases to $150{ }^{\circ} \mathrm{C}$ or more, the DRX is basically completed. Combining the analysis result of one-parameter method, it can be concluded that the critical stress of DRX decreases and DRX becomes easy when temperature increases. The result is in accordance with the analysis of Huang et al. [19], which showed that critical stress decreases when DRX occurs easily. Hence, it can be concluded that the critical conditions of DRX analyzing by one-parameter method are reliable.

\section{Discussion}

Metallographic observation confirmed that the pulse current can accelerate the occurrence of DRX. However, the DRX is not completed at room temperature and $100{ }^{\circ} \mathrm{C}$ until the temperature reaches over $150{ }^{\circ} \mathrm{C}$. The research showed that critical stress and peak stress have certain correlation [20]. The critical stresses of DRX of AZ31 alloy at different temperatures with $150 \mathrm{~Hz} / 50 \mathrm{~V}$ parameter can be obtained from Fig. 3d, which is shown in Table 1. As can be seen in Table 1, the critical stresses of DRX decrease with increasing temperature. The critical stresses are near the peak stress at room temperature and $100{ }^{\circ} \mathrm{C}$. Based on microstructure evolution analysis above, the DRX occurs incompletely under this condition. After temperature reaches 150 and $200{ }^{\circ} \mathrm{C}$, the critical stresses are far below the peak stress and DRX occurs fully. Thus, it can be deduced that the sooner DRX occurs, the better for DRX completes.

Bao et al. [21] reported that the influence of the current on flow stress has a threshold value, and the effect can be
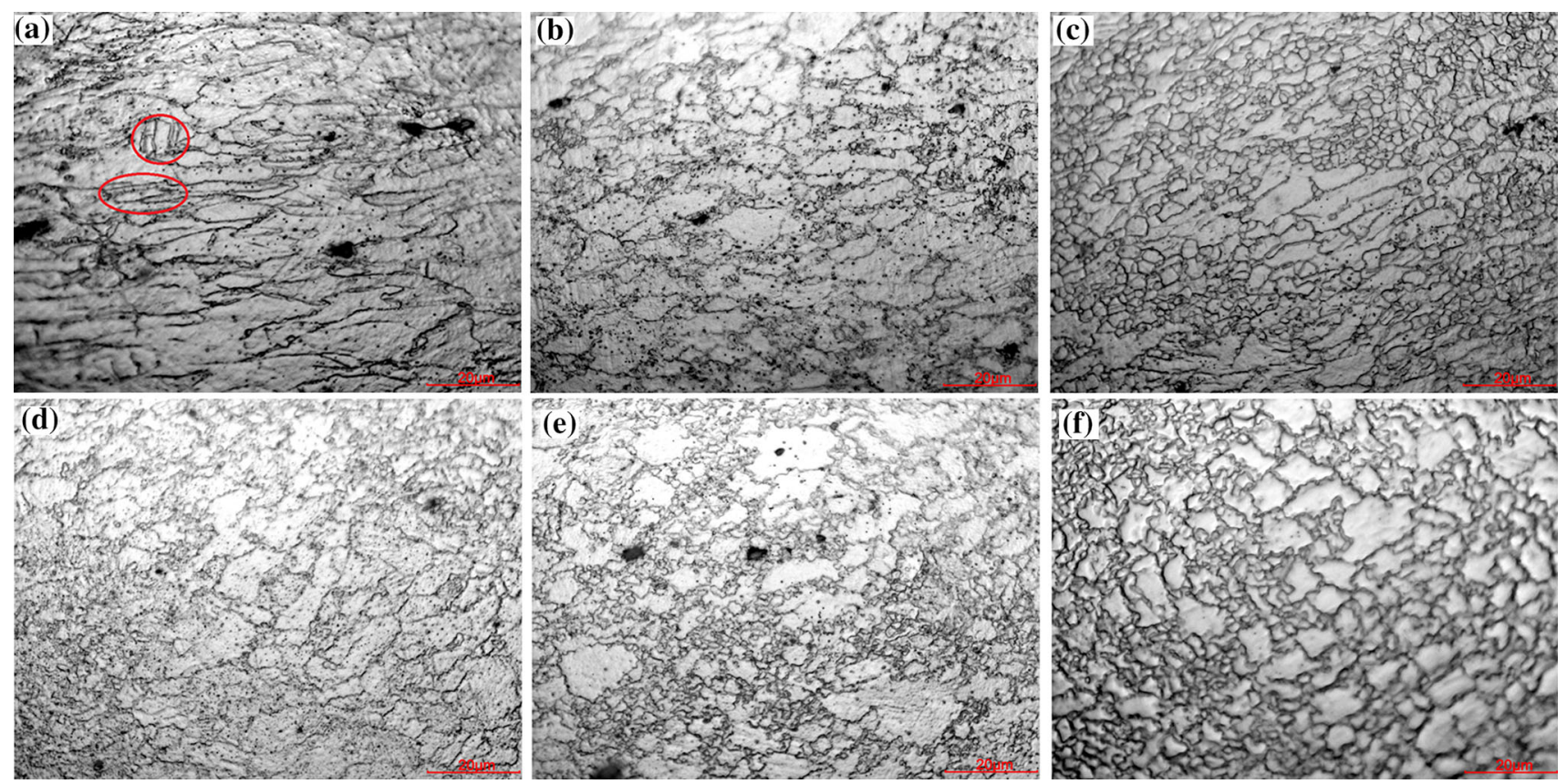

Fig. 4 Microstructures of tensile specimens at: a, b $150{ }^{\circ} \mathrm{C}, 200{ }^{\circ} \mathrm{C}$ without current; c-f Room temperature, $100{ }^{\circ} \mathrm{C}, 150{ }^{\circ} \mathrm{C}, 200{ }^{\circ} \mathrm{C}$ with current, respectively 
Table 1 Critical stress for DRX at different temperatures

\begin{tabular}{lll}
\hline Temperature $\left({ }^{\circ} \mathrm{C}\right)$ & Critical stress $(\mathrm{MPa})$ & Peak stress $(\mathrm{MPa})$ \\
\hline Room temperature & 282.8 & 284.8 \\
100 & 196.9 & 198.7 \\
150 & 118.5 & 158.8 \\
200 & 94.9 & 125.6 \\
\hline
\end{tabular}

enhanced sharply after the threshold. As a result, higher voltage test is carried out to study the influence of the current on DRX of AZ31 alloy at room temperature. The microstructure of the specimen stretched in $150 \mathrm{~Hz} / 70 \mathrm{~V}$ is shown in Fig. 5, which shows the uniform DRX equiaxed grains. It is indicated that the DRX is fully completed with an electropulse of $150 \mathrm{~Hz} / 70 \mathrm{~V}$ at room temperature. The critical stress for DRX under this condition is also analyzed by one-parameter approach, and the obtained critical stress and peak stress are 177.2 and 229.2 MPa, respectively. The critical stress and peak stress with an electropulse of $150 \mathrm{~Hz} / 70 \mathrm{~V}$ were used to determine the relationship between critical stress and peak stress as discussed below. And these values used to determine the relationship between critical stress and peak stress are shown in Table 2.

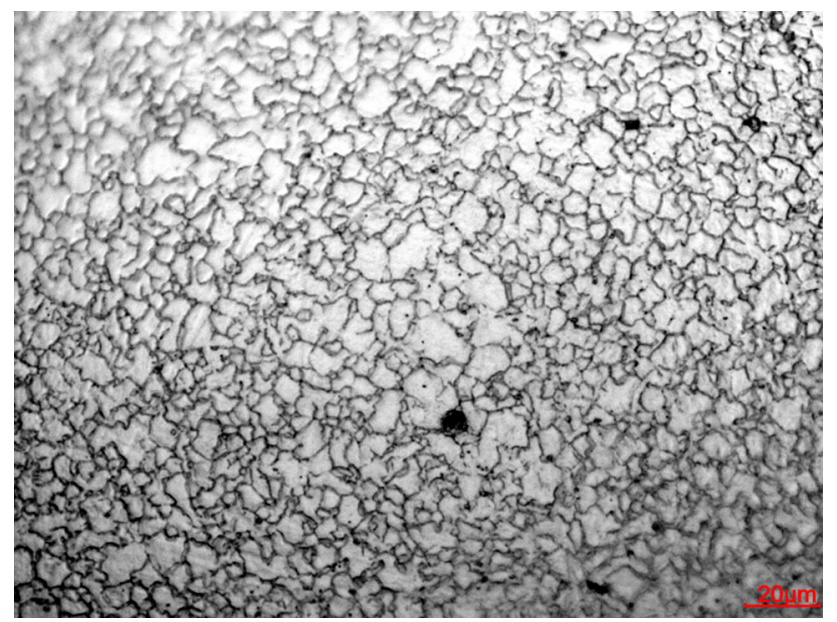

Fig. 5 Microstructure of tensile specimen at $150 \mathrm{~Hz} / 70 \mathrm{~V}$

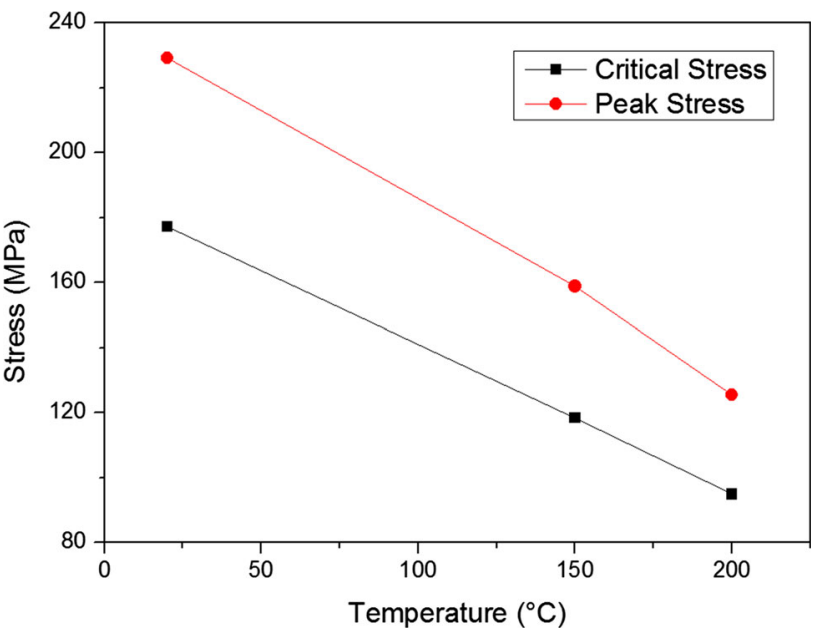

Fig. 6 Curves of $\sigma_{\mathrm{c}}, \sigma_{\mathrm{p}}$ versus $T$ for AZ31 with pulse current

The curves of the critical stress $\left(\sigma_{\mathrm{c}}\right)$ versus temperature $(T)$ and the peak stress $\left(\sigma_{\mathrm{p}}\right)$ versus $T$ at different temperatures with pulse current are shown in Fig. 6. It is shown that the critical stress and the peak stress decrease with increasing temperature, and keeping similar linear relationship with temperature. For conventional warm-hot forming of $\mathrm{Mg}$ alloy, the critical stress and the peak stress meet the relationship: $\sigma_{\mathrm{c}}=(0.75-0.85) \sigma_{\mathrm{p}}$ [7]. When the pulse current is applied, the relationship obtained in this present work is $\sigma_{\mathrm{c}}=(0.746-0.773) \sigma_{\mathrm{p}}$. By contrast, the critical stress decreases with pulse current. It is indicated that the pulse current can accelerate the formation of DRX of AZ31alloy.

\section{Conclusions}

Tensile tests with and without different pulse current have been carried out in this work; the effect of temperature and pulse current on the critical condition of DRX of AZ31 alloy have been studied and discussed, and several conclusions are obtained:

1. DRX of AZ31 alloy occurs at $200{ }^{\circ} \mathrm{C}$ without pulse current. When pulse current with $150 \mathrm{~Hz} / 50 \mathrm{~V}$ parameter is applied at room temperature, DRX can take place while the DRX is not completed. Under higher pulse current parameters of $150 \mathrm{~Hz} / 70 \mathrm{~V}$, DRX of
Table 2 Values used to determine the relationship between critical stress and peak stress

\begin{tabular}{llll}
\hline Temperature $\left({ }^{\circ} \mathrm{C}\right)$ & Electropulse parameters & Critical stress $(\mathrm{MPa})$ & Peak stress $(\mathrm{MPa})$ \\
\hline Room temperature & $150 \mathrm{~Hz} / 70 \mathrm{~V}$ & 177.2 & 229.2 \\
150 & $150 \mathrm{~Hz} / 50 \mathrm{~V}$ & 118.5 & 158.8 \\
200 & $150 \mathrm{~Hz} / 50 \mathrm{~V}$ & 94.9 & 125.6
\end{tabular}


AZ31 alloy is basically completed at room temperature.

2. Based on the analysis result of DRX of AZ31 alloy on one-parameter approach, the relationship between the critical stress and the peak stress obtained in this present work is $\sigma_{\mathrm{c}}=(0.746-0.773) \sigma_{\mathrm{p}}$.

Acknowledgements The authors would like to acknowledge the financial support from the Natural Science Foundation of Shandong Province (Grant No. ZR2016EEM25), the China Postdoctoral Science Foundation (2016M592184).

\section{References}

[1] J. Koike, T. Kobayashi, T. Mukai, H. Watanabe, M. Suzuki, K. Maruyama, K. Higashi, Acta Mater. 51, 2055 (2003)

[2] A. Galiyev, R. Kaibyshev, G. Gottstein, Acta Mater. 49, 1199 (2001)

[3] A. Manonukul, F.P.E. Dunne, Acta Mater. 47, 4339 (1999)

[4] E. Poliak, J. Jonas, ISIJ Int. 43, 684 (2003)

[5] E.I. Poliak, J.J. Jonass, Acta Mater. 44, 127 (1996)

[6] S.I. Kim, Y.C. Yoo, Mater. Sci. Eng. A 2, 108 (2001)
[7] G. Huang, B. Qian, L. Wang, J.J. Jonas, Rare Met. Mater. Eng. 36, 2080 (2007)

[8] S.J. Livesey, D.X.R. Priestner, J. Collins, Scripta Mater. 44, 803 (2001)

[9] J.S. Andrawes, T.J. Kronenberger, T.A. Perkins, J.T. Roth, R.L. Warley, Mater. Manuf. Process. 22, 91 (2007)

[10] K.F. Yao, P. Yu, J. Wang, W. Fang, M.X. Zheng, Acta Metall. Sin. (Engl. Lett.) 14, 341 (2001)

[11] H. Conrad, N. Karam, S. Mannan, Scripta Met. 17, 411 (1983)

[12] Z.S. Xu, Y.X. Chen, Scripta Met. 22, 187 (1988)

[13] J.W. Park, H.J. Jeong, S.W. Jin, M.J. Kim, K. Lee, J.J. Kim, S.T. Hong, H.N. Han, Mater. Charact. 133, 70 (2017)

[14] Z. Xu, G. Tang, S. Tian, F. Ding, H. Tian, J. Mater. Process. Technol. 182, 128 (2007)

[15] H. Liao, G. Tang, Y. Jiang, Q. Xu, S. Sun, J. Liu, Mater. Sci. Eng. A 529, 138 (2011)

[16] Q. Xu, G. Tang, Y. Jiang, G. Hu, Y. Zhu, Mater. Sci. Eng. A 528, 3249 (2011)

[17] X.R. Chu, S.X. Lin, Z.M. Yue, J. Gao, C.S. Zhang, Mater. Sci. Technol. 31, 1601 (2015)

[18] H. Yoshinaga, R. Horiuchi, Trans. JIM 4, 1 (1963)

[19] K. Liu, X. Dong, H. Xie, F. Peng, Mater. Sci. Eng. A 623, 97 (2015)

[20] Z.T. Wang, Y.T. Deng, S.H. Zhang, T. Mater, Heat Treat. 35, 193 (2014)

[21] W. Bao, X. Chu, S. Lin, J. Gao, Mater. Design 87, 632 (2015) 